\title{
Potential of cypermethrin or diazinon and their combined action with piperonyl butoxide (PBO) against Periplaneta americana L
}

\author{
A S. M .Shafiqur Rahman and M.Y. Akter \\ Department of zoology, University of Rajshahi, Rajshahi 6205, Bangladesh. \\ Key words: Periplaneta americana, diazinon, cypermethrin, $\mathrm{LD}_{50}$, synergist
}

Cockroaches are high priority urban pests because their aesthetically unappealing damage stored products and household goods and transmit diseases. (Ebeling, 1978). It becomes a public health problem due to their association with human waste and disease and their ability to move from sewers into homes and commercial establishment. They are well known pest of considerable economic and medical importance (Cameron, 1956). Cockroaches also a mechanical vector of several communicable diseases like gastroenteritis and food poisoning (Bitter, 1949; Eades et al, 1954) transmit Bacillus staphylococci poliomyelitis viruses and destructive mould (Sylverton et al., 1952; Morrel, 1991). There are almost 4,00 species of cockroaches (Service, 1980). Among them American cockroach, Periplaneta americana L. is an obnoxious, omnivorous and filthy domestic pest of tropical zone

Various control measures has been applied to control cockroaches. Chemical control methods using synthetic insecticides has been conventionally used for controlling cockroaches in most part of the world (Pal, 1994; Schofield, 1993) but failure of the cockroaches control program is resistance of the insects due to repeated use of different insecticides. The development of resistance against insecticides by cockroaches and other arthropods of medical importance since 1960's have been later reported by the WHO (1985).Thus alternative cheaper vector control methods which require little or no soplusticated technology, but give excellent results (Minjas \& Sarda, 1986). The present paper describes the effect of diazinon and cypermethrin and their combined action with a known synergist PBO against the American cockroach, P. americana under laboratory condition.

Bioassays were carried out by micro topical application using a Hamilton micro syringe $(\mathrm{ml})$ with canulae (G 36X3) using the procedure of Georghiou \& Bowen (1966), Heinrichs et al (1980), A micro-syringe calibration using mercury was done before the tests. Each bioassay included a minimum of five concentrations of insecticides and an acetone treated control. The mixture of inscticides and piperonyl butoxide (PBO) were used in different ratios( viz.1:1,1:2 and 1:5). Five-day-old adult cockroaches were used for bioassay. Treatment was made by applying $1.0 \mu \mathrm{l}$ solution of test insecticides to the dorso-thoracic region of individual insect under anesthetic condition with five replications. After treatment the insects were placed in glass beakers (500 ml.) containing a small amount of food in an incubator at $30^{\circ} \mathrm{C}$.

Initial bioassays were carried out to establish the effect of single treatment. It was observed that cypermethrin was more toxic than diazinon. The topical $\mathrm{LD}_{50}$ values of diazinon was $511.55 \mathrm{ng} / \mathrm{insect}$ where as it was recorded as $313.04 \mathrm{ng}$ /insect in cypermethrin (Table 1). Ho et al, (1994) studied the toxicity of diazinon against the cockroach and reported that the diazinon was more effective to control cockroach. Lukua \& Manokora (1997) studied the toxicity of some pyrethroid insecticides against the cockroach and reported that the cockroaches died immediately after application of permethrin.

Combining PBO both diazinon and cypermethrin indicated a synergistic action at 1:5 ratio followed by 1:2 and 1:1 ratios. The cotoxicity coefficient values also indicated that there was an increase in synergism with increase PBO ratios. The isobole for mixtures of both test insecticides with $\mathrm{PBO}$ are of similar shape indicating that a similar response was talking place. The effect of PBO to insects has been studied by several investigators. It is now generally recognized that PBO produces to synergistic effect by inhibiting the detoxifying enzymes within insect body (Casida, 1970; Davenport \& Wright, 1985).

In the present investigation PBO increased the toxicity of both diazinon and cypermethrin against $P$. americana. This result therefore, suggests that inhibition of oxidative detoxification might be involved to some extent. The results of synergism are similar to those reported by Dai \& Sun (1984), Chapman (1985) Meyer et al, (1987), Scott \& Georghoiu (1986)

\section{Acknowledgement}

The authors are grateful to the Chairman, Department of Zoology, Rajshahi University for necessary laboratory facilities. 
Table 1. $\mathrm{LD}_{50}$, regression equation, Co-toxicity coefficient (CC) of mixtures of cypermethrin or diazinon and piperonyl butoxide (PBO) at different ratios applied to P. americana.

\begin{tabular}{lcccccc}
\hline \multirow{2}{*}{ Insecticide } & $\begin{array}{c}\text { LD }_{\mathbf{5 0}} \\
\text { (ng/insect) }\end{array}$ & $\begin{array}{c}\text { Ratio } \\
\text { Insecticide:PBO }\end{array}$ & $\begin{array}{c}\text { Combined LD } \\
\text { (ng/insect) }\end{array}$ & $\begin{array}{c}\text { Insecticides LD } \\
\text { ng/insect) }\end{array}$ & $\begin{array}{c}\text { PBO LD }_{\text {50 }} \\
\text { (ng/insect) }\end{array}$ & $\begin{array}{c}\text { Cotoxicity } \\
\text { Coefficient }\end{array}$ \\
\hline \multirow{3}{*}{ Diazinon } & \multirow{2}{*}{511.56} & $1: 1$ & 911.17 & 455.50 & 455.50 & 112.305 \\
& & $1: 2$ & 642.90 & 214.30 & 428.60 & 238.70 \\
& & $1: 5$ & 630.61 & 105.10 & 525.50 & 486.718 \\
\hline \multirow{3}{*}{ Cypermethrin } & \multirow{2}{*}{313.04} & $1: 1$ & 141.83 & 70.917 & 70.917 & 372.33 \\
& & $1: 2$ & 175.17 & 58.390 & 116.781 & 1475.00 \\
& & $1: 5$ & 269.92 & 44.987 & 224.938 & 2840.74 \\
\hline
\end{tabular}
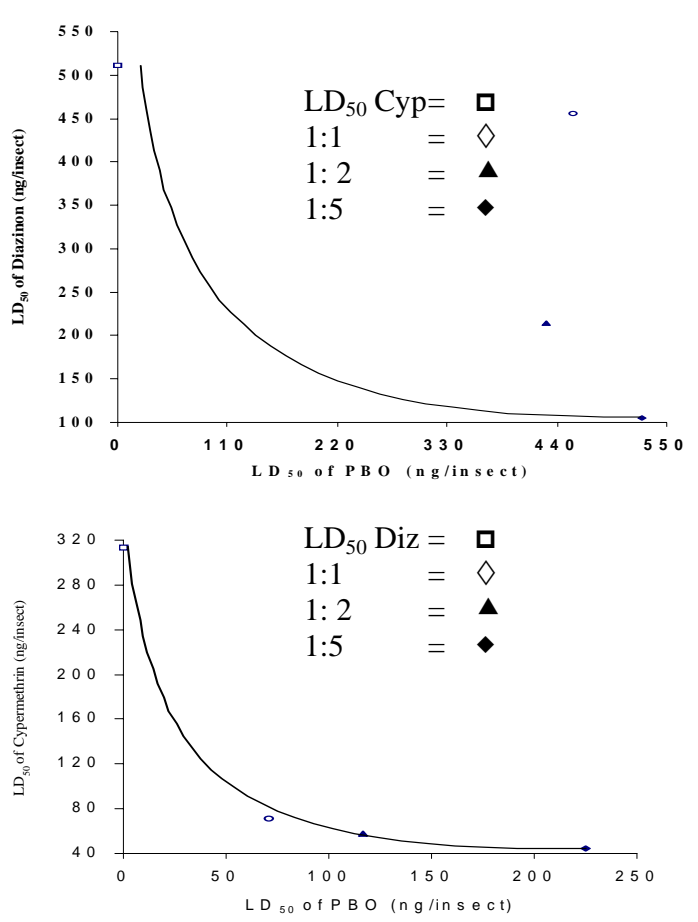

Fig.1: Isobolograms of diazinon (Above) and Cypermethrin (Below) with $\mathrm{PBO}$ against $P$. americana adults.

\section{References}

Bitter, R. S. \& Williams, O. B. 1949. Enteric organisms from the American cockroach. J. Infect Dis. 85: 87-90.

Cameron, F.1956. On the parasites and predators of the cockroach, II Evania appendigaster Bull.Ent.Res. 48: 1909-209.

Casida, J. E. 1970. Mixed function oxidizes involvement in the biochemistry of insecticides synergism. J. Chem. Agric. Food 18: 753.

Chapman, P. A. 1985. The resistance to eighteen toxicities of a strain of Musca domestica collected from a farm in England. Pestic Sc. 16: 271-276.

Dai, S.M \& Sun,C.N. 1984. pyrethroid resistance and synergism in Nilaparvata lugens in Taiwan. J.Econ.Entomol.77: 891-897.

Davenport, A. P. \& Wright, D. J. 1985. Toxicity of Chlorodeiform and Amitraj to the Egyptian leafworm (Spodoptera littorlis). Pestic. Sci. 16: 81-87.
Eades, R.B., Zuben, F.J Von,Bennett,S.E \& Walker,O.L 1954 Studies on cockroaches In a municipal sewerage system Amer. J. Trop.Med.Hyg. 3(6):1092-1098.

Ebeling, W.1978. Urban Entomology. J.Univ.Calif. 695.

Georghipou G.P \& Bowen, W.R. 1966. Analysis of housefly resistance to insecticides in California. J.Econ.Entomol. 59(1): 204-214.

Heinrichs, W.E.A. Chelliah, S. \& Valencia, N. 1980. Manual for testing insecticides on rice. IRRI Los Banos. Philippin pp .14-15.

Ho, S. H. Goh, P. M. \& Leong, F. C.W. 1994. Toxicity of some Organophosphorus an Carbamet insecticides to Periplaneta americana (L) an inhibition of non specific esterases by the insecticides. Int. pest. Cont. 36( b): 153-158.

Lukua, N. \& Manokora, V. 1997. Biological activity of permethrin, phenothrin on D- phenothrin on Periplaneta americana on Blatella germanica Cockroaches. East African Journal,74(4):1007-10.

Meyer, J. A. Geoghiou, G.P \& Hewley, M.K 1987. Housefly resistance to permethrin of Southern California Davies. J.Econ.Entomol. 8: 363-340.

Morrel, C.C. 1991. Bacteriology of the cockroach. Brit. Med J. 2: 1531-1532.

Pal, R. 1994. Program of genetic control of mosquito E. Elsevieer: North- Holland 73-95.

Schofield, C. J. 1993. The polices of malaria vector control. Bull. Ent. Res. 83 : 1-6.

Scott, J. G. \& Georghiou,G.P 1986. Mechanism for possible high levels of permethrin resistance in the housefly. Pestic Sci.17: 195-205

Service,M.W.1980. A guide to medical Entomology. The Macmillan Press. 150.

Sylverton, J.T Fischer, R.J. \& Smith, S.A. 1952. The cockroaches as natural extra human source of poliomyelitis virus. Fed. Proc. 11: 483.

WHO (World Health Organization) 1985. Vector control series. Cockroaches. Training and information guide. Vector Biology Control Division, pp. 37.

Manuscript received on 25.06.2008, accepted on 15.09.2008 